\title{
APPLICABILITY OF BOLTON'S ANALYSIS AND KESLING SET-UP- A STUDY ON CHHATTISGARH POPULATION
}

\author{
Bhawana Chandraker', Amit Chandraker², Tanuj Chaudhary ${ }^{3}$
}

${ }^{1} B D S$, MDS Orthodontics, Durg, Chhattisgarh.

2Medical Officer, Special Task Force Unit Hospital, Baghera, Chhattisgarh, MBBS Chhattisgarh Institute of Medical Sciences, Bilaspur, Chhattisgarh.

${ }^{3}$ Senior Lecturer, Department of Orthodontics, Maitri Dental College, Anjora, Durg, Chhattisgarh. ABSTRACT

\section{BACKGROUND}

Orthodontic treatment planning poses significant challenges for clinicians with respect to their ability to provide the most predictable results for patients in a safe, effective and efficient manner. Prediction of accurate space has prime role in diagnosis and treatment planning in Orthodontics.

Aims and Objectives- The aim of the study was to determine whether the mean overall and anterior ratio of Chhattisgarh population would significantly differ from Caucasian (Bolton's) values. To evaluate extraction as a parameter in determination of Bolton ratio and compare it with non-extraction case while using Kesling diagnostic setup.

\section{MATERIALS AND METHODS}

The sample was screened from the general OPD of Department of Orthodontics and Dentofacial Orthopaedics, Maitri Dental College, Anjora, Durg as well as from the students of Maitri Dental College. Camps were set up in Maitri Nursing College and students diagnosed with orthodontic problems and various other ailments were called to the OPDs for treatment. Patients who were able to cooperate, having complete permanent dentition (first molar to first molar), no caries, no proximal restoration, no attrition and no dental anomaly. All teeth should be fully erupted to the occlusal plane. Patients having at least anterior crowding were included. 33 extraction and 67 non-extraction cases were included.

\section{RESULTS}

Standard descriptive statistics (mean, standard deviation and standard error of mean) were calculated for each sample. Comparison was made between the extraction and non-extraction subjects, and also between the present established overall ratio and anterior ratio. ' $\mathrm{T}$ ' test was used for comparison of extraction and non-extraction and comparison was made between Bolton's study (Caucasian population) and recent study (Chhattisgarh population).

\section{CONCLUSION}

The Bolton analysis has been shown to be a reliable diagnostic tool for assessing tooth size discrepancy and Kesling diagnostic setup in the treatment planning of dental malocclusions.

\section{KEYWORDS}

Bolton Analysis, Kesling Set-Up, Chhattisgarh Population.

HOW TO CITE THIS ARTICLE: Chandraker B, Chandraker A, Chaudhary T. Applicability of Bolton's analysis and Kesling set-up- a study on Chhattisgarh population. J. Evolution Med. Dent. Sci. 2018;7(13):1557-1562, DOI: 10.14260/jemds/2018/352

\section{BACKGROUND}

Prediction of accurate space has prime role in diagnosis and treatment planning in orthodontics. According to Proffit and Fields, ${ }^{1}$ space analysis should be done accurately before any Orthodontic treatment. Tooth size discrepancy is defined as a disproportion among the sizes of individual teeth. ${ }^{1}$ Orthodontic treatment planning poses significant challenges for clinicians with respect to their ability to provide the most predictable results for patients in a safe, effective and efficient manner. Similarly, orthodontists must address the challenge of assessing treatment results in an objective manner. ${ }^{2}$

'Financial or Other Competing Interest': None.

Submission 13-02-2018, Peer Review 08-03-2018,

Acceptance 15-03-2018, Published 24-03-2018.

Corresponding Author:

Dr. Bhawana Chandraker,

New Adarsh Nagar, Street No. 1,

Zone 1/C Nalapar, Near Pandit Ji Niwas,

Durg-491001, Chhattisgarh.

E-mail: bhawana.chandrakar@gmail.com

DOI: $10.14260 /$ jemds $/ 2018 / 352$

\section{(c) $(7)(-)$}

A number of quantitative tools have been developed to aid in these endeavours including the Bolton analysis of inter-arch tooth-size relationships.

Plaster casts have long been in use for the analysis and treatment planning of all orthodontic cases. Although, they have been considered study casts, much of the study has been merely speculation as to what might be accomplished orthodontically. Diagnosis through rearrangement of the plaster teeth was overlooked. Good orthodontic casts not only provide exact duplicates of every tooth in the mouth, but they also give a fairly accurate pattern of the apical base. ${ }^{3}$

The development of the tooth-size analysis ratios, which are to be the basis of this investigation was presented in 1952. Since that time, these ratios have been applied to many clinical orthodontic cases. ${ }^{3,4}$ It is the purpose of this study to review the establishment of the analysis and from this review attempt to present practical and detailed examples of the measurement and application of the information derived from the analysis procedures. Two equations to analyse the mesiodistal tooth size ratio between permanent maxillary and mandibular teeth. Anterior Bolton ratio was calculated for six anterior teeth 
(canine to canine) and the overall Bolton ratio was calculated for the anterior and posterior teeth, full arch excluding second and third molars. ${ }^{5}$

Plaster casts of the dental arches play a key role in orthodontic diagnosis since. Besides revealing the occlusal conditions of the patient in the three dimensions of space, they allow for the performance of many different analysis that assist in orthodontic treatment planning. These include analysis of space discrepancy in mixed and permanent dentition, dental arch symmetry, Bolton discrepancy and orthodontic setup procedure. ${ }^{6}$

One of the basic fundamentals with which the orthodontist has to deal in reconstructing the denture is tooth size, specifically the mesiodistal width of the teeth. Surprisingly, few investigations have been conducted on this phase of orthodontics, as evidenced by the scarcity of literature related to the subject. The primary purpose of this study was to analyse a group of excellent occlusion and determine whether or not mathematical ratios could be set up between total lengths of dental arches as well as between segment of dental arches. It was hoped that a method of evaluating tooth size would be found, which would be an aid in diagnosis and treatment planning of orthodontic cases and also help in determining the functional and aesthetic outcome of the case. ${ }^{7}$

\section{MATERIALS AND METHODS}

The sample was screened from the general OPD of Department of Orthodontics and Dentofacial Orthopaedics, Maitri Dental College, Anjora, Durg as well as from the students of Maitri Dental College. Camps were setup in Maitri Nursing College and students diagnosed with orthodontic problems and various other ailments were called to the OPDs for treatment.

\section{Inclusion Criteria}

Patients who were able to cooperate, having complete permanent dentition (first molar to first molar), no caries, no proximal restoration, no attrition and no dental anomaly. All teeth should be fully erupted to the occlusal plane. Patients having at least anterior crowding were included.

\section{Exclusion Criteria}

Congenital anomalies/ malformations, previous orthodontic treatment, allergic to impression material, dental arches having any crown and bridge prostheses, any deformity in maxilla or mandible.

\section{Midline Registration}

Coinciding the upper and lower dental midlines is one of the treatment objectives, be it for aesthetic and/ or functional purposes, be it to accomplish adequate dental intercuspation in the posterior region of the dental arches. For this reason, the initial position of the midlines deserves utmost attention. ${ }^{4,8}$ To evaluate such position, the patient must be in a standing position during the clinical extraoral examination with the Frankfort horizontal plane parallel to the ground and facing the operator. One must then note the position of the upper and lower dental midlines relative to the facial midline. 6

\section{Tooth Identification and Cutting}

Before their removal from the base of the models, the teeth should be numerically identified with pencil $0.5 \mathrm{~mm}$ on the lingual surface, to prevent them from being confused when mounting the setup. For the removal of the upper and lower teeth, a line must be drawn limiting the region of the alveolar ridge, approximately $3-4 \mathrm{~mm}$ from the cervical region of the teeth. The models must be drilled in the buccolingual direction with the aid of a round bur mounted in a handpiece on the limited horizontal line near the midlines of the teeth. The hole diameter should be about 2 $\mathrm{mm}$, sufficient for inserting a thin spiral saw. The explorer highlight the interdental limits providing a guide for the fracture line. ${ }^{9}$ Only then should a light finger pressure more or less should be applied to weaken the embrasures and separate the teeth. The plaster stump of each tooth should be stripped with a steel or tungsten dental bur slenderising the stump, while carefully preserving the mesiodistal dimension of each tooth without removing the dentogingival limit. 6

\section{Tooth Mounting}

To mount the teeth, the model base should be prepared in the following sequence: Complete filling of the central groove in the alveolar base with a layer of melted red wax. Incisor is positioned in the red wax according to the changes proposed in the treatment plan, considering proclination, retraction, intrusion or extrusion. ${ }^{10}$ Next, the remaining teeth are positioned using as reference to the arch wire form which best represents the original dental arch form. Once one of the lower quadrants has been fully mounted, the same procedures should be repeated in mounting the upper teeth on the same side ensuring the best possible intercuspation while maintaining the vertical and transverse dimensions. After mounting is completed on one side, one must repeat all procedures on the other side of the dental arch. ${ }^{6}$

\section{Statistical Analysis}

Standard descriptive statistics (Mean, standard deviation, standard error of mean) were calculated for each sample. Calculated mean was compared between study population and Bolton's group.

' $\mathrm{T}$ ' test used for comparison of overall and anterior ratio between extraction and non-extraction cases. The ' $t$ ' value was calculated and found statistically significant or not as ' $p$ ' value $<0.001$ or ' $p$ ' value $>0.001$. Thus, when compared to extraction and non-extraction group overall and anterior ratio.

Statistical Package for Social Sciences (SPSS) system version 12.0 with the level of statistical significant determinant is used in this study.

\begin{tabular}{|c|c|c|}
\hline Anterior Ratio & $\begin{array}{c}\text { Study } \\
\text { Population }\end{array}$ & $\begin{array}{c}\text { Bolton's Study } \\
\text { (Caucasian } \\
\text { Group) }\end{array}$ \\
\hline Sample Size & 100 & 55 \\
\hline Mean & 70.52 & 78.4 \\
\hline Standard Deviation & 2.67 & 2.33 \\
\hline Standard Error & 0.27 & 0.23 \\
\hline $\begin{array}{c}\text { Table 1. Statistical Comparison between Chhattisgarh } \\
\text { Population versus Bolton's Caucasian's Group } \\
\text { "Anterior Ratio" }\end{array}$ \\
\hline
\end{tabular}




\begin{tabular}{|c|c|c|}
\hline $\begin{array}{c}\text { Overall } \\
\text { Ratio }\end{array}$ & $\begin{array}{c}\text { Study } \\
\text { Population }\end{array}$ & $\begin{array}{c}\text { Bolton's Study } \\
\text { (Caucasian Group) }\end{array}$ \\
\hline Sample Size & 100 & 55 \\
\hline Mean & 99.76 & 92.47 \\
\hline Standard Deviation & 4.32 & 1.94 \\
\hline Standard Error & 0.43 & 0.19 \\
\hline
\end{tabular}

Table 2. Statistical Comparison between Chhattisgarh Population versus Bolton's Caucasian' Group “Overall Ratio"

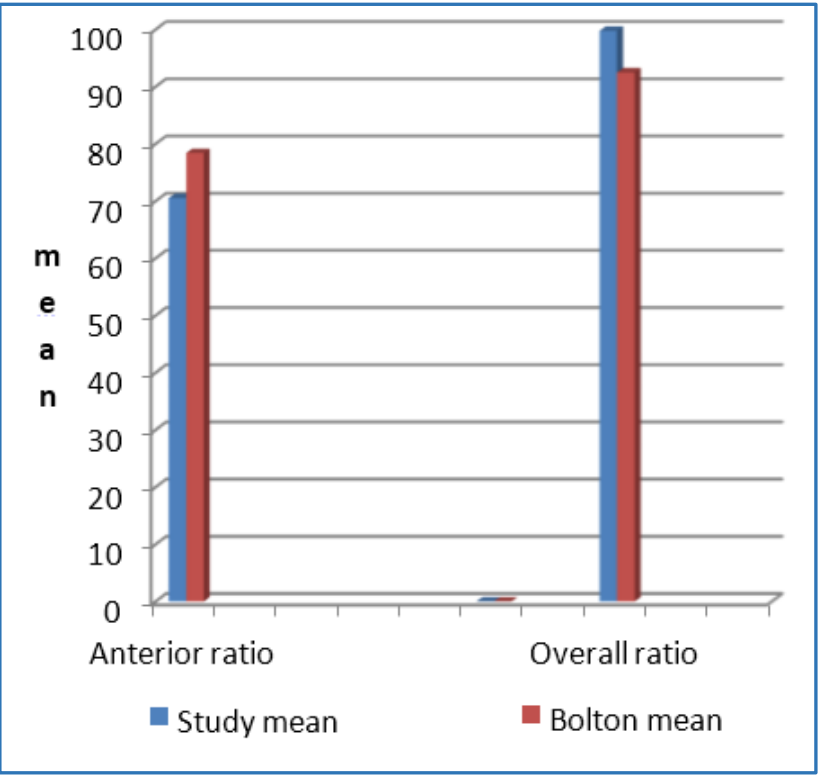

Graph 1. Statistical Comparison between Chhattisgarh Population and Bolton's Group (Caucasian Group) “Overall Ratio and Anterior Ratio"

In clinical orthodontics, more often than not interproximal stripping is instituted in non-extraction cases to achieve space for final alignment.

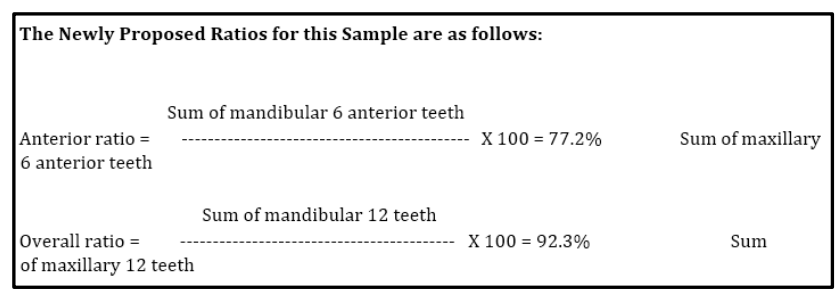

Independent " $\mathrm{T}$ " test comparing the anterior tooth size ratio derived from the study sample and its equivalent mean value of 77.2 suggested by Bolton and independent "T" test comparing the mean of the overall tooth size ratio derived from the study sample and its equivalent mean value of 91.3 suggested by the Bolton study, 1958.

\begin{tabular}{|c|c|c|c|c|}
\hline Ratio & $\begin{array}{c}\text { Extraction } \\
\text { Group } \\
\text { (N=33) }\end{array}$ & $\begin{array}{c}\text { Non- } \\
\text { Extraction } \\
\text { Group } \\
\text { (N=67) }\end{array}$ & $\begin{array}{c}\text { T } \\
\text { value }\end{array}$ & P value \\
\hline Overall Ratio & & & & \\
\hline Mean & 99.41 & 91.67 & 0.392 & $\begin{array}{c}0.696 \\
\text { Not } \\
\text { Significant }\end{array}$ \\
\hline $\begin{array}{c}\text { Standard } \\
\text { Deviation }\end{array}$ & 0.66 & 4.47 & & \\
\hline
\end{tabular}

\begin{tabular}{|c|c|c|c|c|}
\hline $\begin{array}{c}\text { Standard } \\
\text { Error of Mean }\end{array}$ & 3.78 & 0.55 & & \\
\hline Anterior Ratio & & & & \\
\hline Mean & 48.37 & 36.67 & 1.162 & $\begin{array}{c}0.248 \\
\text { Not } \\
\text { Significant }\end{array}$ \\
\hline $\begin{array}{c}\text { Standard } \\
\text { Deviation }\end{array}$ & 2.76 & 1.88 & & \\
\hline $\begin{array}{c}\text { Standard } \\
\text { Error of Mean }\end{array}$ & 0.49 & -0.23 & & \\
$\begin{array}{c}\text { Table 3. Statistical Comparison of the Overall and the } \\
\text { Anterior Ratio between the Extraction and Non-Extraction } \\
\text { Case }\end{array}$ \\
\hline
\end{tabular}

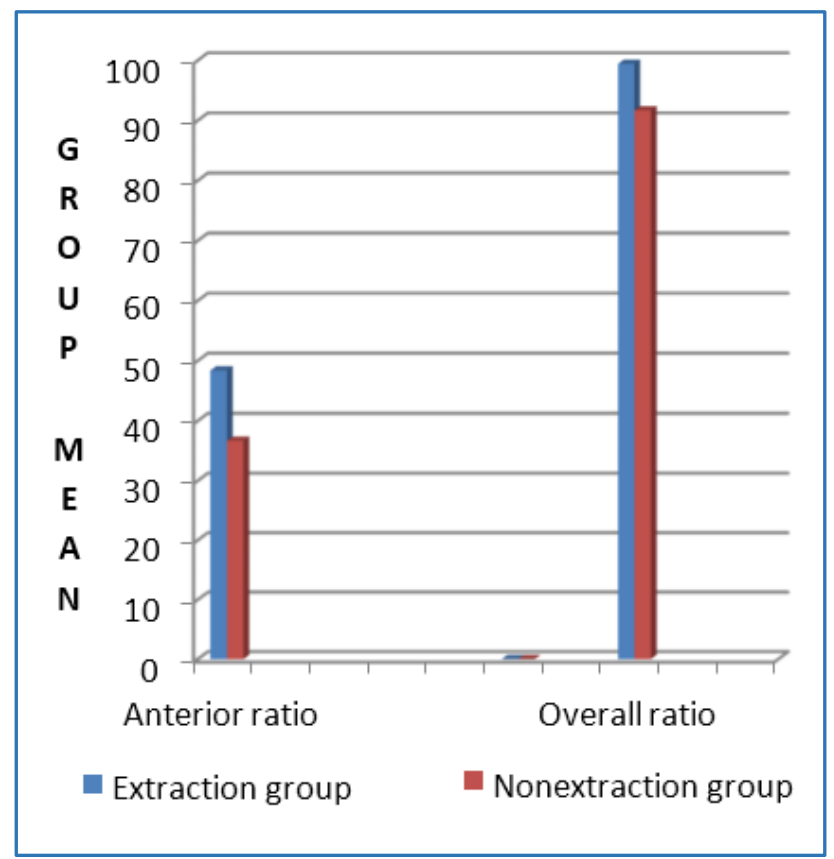

Graph 2. Overall and Anterior Ratio Comparison between Extraction and Non-Extraction Case

An independent " $\mathrm{T}$ " test comparing the overall tooth size ratio of the study with the Bolton's study was computed. The test suggests that the anterior ratio variable in the study does not show statistically significant differences from the norms derived from the Bolton's study.

\section{RESULTS}

The study was aimed to evaluate the mesiodistal width of the dentition, Bolton's anterior and overall ratio and evaluate separately the anterior and posterior ratios and to identify the area of tooth size discrepancy. The study comprised a total of one hundred sample, which has 33 samples which are Extractions and 67 are Non-Extractions. The anterior ratio was significantly higher from Bolton's standard, while the overall ratio was not significantly different. The anterior ratio was significantly higher from Bolton's standard, while the overall ratio was not significantly different. The present study shows significant difference in anterior as well as overall ratios of the Chhattisgarh population as compared to Bolton's ratios of Caucasian females. It also shows that there is a statistically significant difference between the overall ratio between extraction and non-extraction and that the overall and anterior ratio is higher in extraction case than in nonextraction case. 


\section{DISCUSSION}

The mean age for the male and female samples were 15 years +/- 3 years and 24 years +/- years respectively. The mean age of our study was in keeping with whose sample age range was 12 to 22 years. In this study, the highest number of boys $(n=14)$ and girls $(n=20)$ were in the age range of 15 to 25 years. ${ }^{11}$ The teeth that were required to perform this study were usually present at this age range; hence, most of the sample falls within this age group. This age group of the sample also represents the age range of most young patients who seek orthodontic treatment. AlKhateeb and Alhaija studied a selected group of teenagers from this age range to minimise the alteration of the mesiodistal tooth dimensions because of factors such as attrition, restorations and caries. ${ }^{12}$ If patients were too young some teeth that had to be measured might not have been present such as the premolars, and if patients were too old interproximal wear and attrition would have resulted in inaccurate measurements being made. ${ }^{13}$ Tooth size discrepancies (TSD) play an important role in orthodontic finishing. The necessity of appropriate tooth size ratios has been well established in the literature and accepted among orthodontists. ${ }^{6}$ A lack of proper relationships between the upper and lower teeth during orthodontic finishing may result in an occlusal relationship that either does not have good coupling in the anterior or suitable cusp-tofossa/embrasure alignment in the posterior. Other factors including incisor angulation and tooth thickness have also been considered as meaningful in achieving an ideal occlusion. ${ }^{14}$ The high prevalence of TSDs in the anterior and posterior regions in this sample indicates the importance of recognising TSDs as part of orthodontic diagnosis. Being aware of tooth size discrepancies prior to initiation of treatment provides an advantage to making decisions for the finishing phase. ${ }^{2}$ Because clinicians would be reluctant to reduce or add tooth size with a discrepancy of \pm 1 SD $8,9,16$, 17,22 and 26.

(Approx. $1.5 \mathrm{~mm}$ clinically or $0.75 \mathrm{~mm}$ each side), several authors have used \pm 2 SD as the benchmark for establishing a clinically significant discrepancy, which is equivalent to approximately $3 \mathrm{~mm}$ or more, an amount more likely to be corrected by removal of tooth structure and/ or prosthetic alteration. The anterior TSD prevalence of $17.6 \%$ agrees with that reported. The total TSD prevalence of $12.1 \%$ falls among those 8, 9, 16, 17, 22 and 26. Published by several others. The \pm 2 SD range generally underestimates the prevalence of a discrepancy and therefore recommend disregarding the Bolton's standard deviation as a measure of the prevalence of clinically significant discrepancy. The prevalence of anterior TSD (greater than \pm 1 SD) of $51.5 \%$ corresponds to the high prevalence reported $(56 \%, \mathrm{n}=$ $300), 2$ but contrasts that reported by Bolton $(29 \%, n=100)$ and Richardson $(33.7 \%, \mathrm{n}=205)$. This difference could possibly be explained by variations due to demographics and ethnicity. ${ }^{15}$ Using standard deviation between what is clinically relevant and what is not does not accurately determine what is needed clinically. In our study, a TSD of $1.5 \mathrm{~mm}$ spread throughout the entire maxillary dentition that represents a clinically insignificant amount, whereas a discrepancy of $1.5 \mathrm{~mm}$ on a lateral incisor would be considered a significant clinical discrepancy. 16
Bolton published his anterior and total ratio means as $77.2 \pm 1.65 \%$ and $91.3 \pm 1.91 \%, 2$ and 4 respectively. The anterior ratio mean was $78.0 \pm 2.56 \%$ and the total ratio mean was $92.7 \pm 1.99 \%$ in this study. This is slightly higher on average than that reported by Bolton. Those with crowding tended to have larger crowns requiring more arch space for alignment. The present study extended this design to test whether there are graded responses between increasing tooth size and increasing severity of malocclusion. ${ }^{17,18}$ That is, (1) Can an association be documented between a subject's tooth size and his extent of tooth-based malocclusion (rotations, displacements, crowding)? and (2) What is the nature of the association? The test design takes the sexual dimorphism of tooth dimensions into account, so that tooth sizes between the sexes do not confound interpretations. The mesiodistal tooth size, Bolton's ratio, arch width and arch length were compared in Class I, Class II division 1, Class II division 2 and Class III sample. ${ }^{19}$

Haoyu Tong studied, compared the changes in numbers in each group before and after extractions of premolars found that some of the male and female patients in the Bolton's normal group moved into the Bolton's small group with each combination of extraction. The change was related to the specific extraction combination and the numbers obviously changed in combinations of four second premolars and upper second and lower first premolars. ${ }^{20,21}$ It shows that some of the patients with normal overall ratios would become those with small ratios after extraction of premolars, especially after removal of four second premolars and upper second and lower first premolars. ${ }^{22}$

We also compared in our study the overall ratios before and after extraction and found that the overall ratios of both extraction and non-extraction. A significant difference was present between before and after in each extraction combination in these two groups. Saatci and Yukay found that extraction of four first premolars create the largest tooth size discrepancy and the difference calculated for all extraction therapies were not significant from each other.23,24 The traditional anterior and overall ratios as prescribed by Bolton will give us an idea regarding whether the mandibular anteriors are in excess or deficient in relation to maxillary anteriors and whether the mandibular total tooth material is in excess or deficient in relation to total maxillary tooth material along with the exact amount of excess or deficiency. ${ }^{25}$ They also give an idea regarding the relation of maxillary and mandibular posteriors to each other, but not the amount of discrepancy. The calculated mean value of posterior ratio can help us to detect the amount of discrepancy in the posterior segment. Thus, it helps us to evaluate specifically which segment, anterior or posterior, is at fault so that achieving a correct end result incorporating all the six keys. In this study choosing sibling pairs rather than twins are as follows: because the number of twins is small in a population and it is difficult to obtain enough pairs for a statistical study. It is important to assess the presence and eruption path of the other molar teeth, as they will form part of the functional dentition. In the lower arch, the first molars were extracted after full eruption of the lower second molars. ${ }^{26}$ There was a reasonably large space requirement in the lower arch, which was beneficial as during alignment there would be less risk of retraction of the 
lower labial segment. Upper anchorage reinforcement was required to maximise the use of upper first molar space. Upper molar space closure can be rapid as second molars rapidly move mesially during treatment. McLaughlin Bennett Trevisi (MBT) prescription bands, which have $10^{\circ}$ of lingual crown torque $\left(20-25^{\circ}\right.$ less than most other prescriptions), are designed to reduce lower molar lingual roll.25,27 Nickel-titanium coil springs were chosen to deliver a constant low-grade force, which generally provides efficient space closure. ${ }^{28}$ Labial crown torque of the lower incisors can be used if required to minimise lower labial segment retraction during space closure. ${ }^{29}$ At the end of space closure, gentle tip-back bends in the wire on the second molars encouraged correction of the root angulations, whilst dead ligatures maintained the crown position. The treatment time when compared to a similar case treated with the extraction of 4 premolars was probably $4-6$ months longer. We agree with the present study where crowding is significantly related to mesiodistal size of both maxillary and mandibular arches. ${ }^{30,31}$

\section{CONCLUSION}

The Bolton analysis has been shown to be a reliable diagnostic tool for assessing tooth size discrepancy and Kesling diagnostic setup in the treatment planning of dental malocclusions. ${ }^{9}$ However, the study has shown that the Bolton's analysis is not only a decisive tool in predicting clinically significant tooth size discrepancies that would prevent from achieving good occlusions. ${ }^{32,33}$

It would be recommended to consider a diagnostic setup in malocclusions showing a significant tooth size discrepancy, especially if the treatment plan included having to do selective dental interproximal reduction (IPR). ${ }^{34,26}$ To avoid any misinterpretations of the analytic readings, another way to determine the need for IPR would be to align both upper and lower dental arches orthodontically and achieve good interarch relation that has been demonstrated in this study. ${ }^{35}$

In the present study, the following Conclusions may be drawn when combining Changes of Numbers and Overall Ratios

- The Bolton's overall ratio decreased after extraction of premolars;

- In some of the patients, normal overall ratios could change to small overall ratios;

- In some of the patients, high overall ratios could change to normal overall ratios after removal of premolars, especially combinations of four second premolars and upper second and lower first premolars. ${ }^{36,10}$

\section{REFERENCES}

[1] Proffit WR. Contemporary orthodontics. $4^{\text {th }}$ edn. Elsevier Health Sciences 2013.

[2] Freeman JE, Maskeroni AJ, Lorton L. Frequency of Bolton tooth size discrepancies among orthodontic patients. American Journal of Orthodontics and Dentofacial Orthopedics 1996;110(1):24-7.

[3] Tomassetti JJ. A comparison of 3 computerized bolton tooth-size analyses with a commonly used method. Angle Orthod 2001;71:351-7.
[4] Araujo E, Souki M. Bolton anterior tooth size discrepancies among different malocclusion groups. Angle Orthod 2003;73(3):307-13.

[5] Bolton WA. The clinical application of a tooth-size analysis. American Journal of Orthodontics 1962;48(7):504-29.

[6] De Araújo TM, Fonseca LM, Caldas LD, et al. Preparation and evaluation of orthodontic setup. Dental Press J Orthod 2012;17(3):146-65.

[7] Bolton WA. Disharmony in tooth-size and its relation to the analysis and tertment of malocclusion. Angle Orthodontist 1958;28(3):113-30.

[8] Santoro M, Galkin S, Teredesai M, et al. Comparison of measurements made on digital and plaster models. Am J Orthod Dentofacial Orthop 2003;124(1):101-5.

[9] Sun MK, Kim JH, Cho JH, et al. What determines dental protrusion or crowding while both malocclusions are caused by large tooth size? Korean J Orthod 2009;39(5):330-6.

[10] Murad SM, Al-Mulla AA. Accuracy of measurements made on digital and study models (A comparative study). MDJ 2010;7(1):71-82.

[11] Radnzic D. Dental crowding and its relationship to mesiodistal crown diameters and arch dimensions. American Journal of Orthodontics and Dentofacial Orthopedics 1988;94(1):50-6.

[12] Zilberman O, Huggare JA, Parikakis KA. Evaluation of the validity of tooth size and arch width measurements using conventional and threedimensional virtual orthodontic models. Angle Orthod 2003;73(3):301-6.

[13] Quimby ML, Vig KW, Rashid RG, et al. The accuracy and reliability of measurements made on computerbased digital models. Angle Orthodontist 2004;74(3):298-303.

[14] Othman SA, Harradine NW. Tooth-size discrepancy and Bolton's ratios: a literature review. Journal of Orthodontics 2006;33(1):45-51.

[15] Kesling HD. The diagnostic setup with consideration of the third dimension. American Journal of Orthodontics 1956;42(10):740-8.

[16] Naduwinmani SL, Naduwinmani JP, Nayak KUS. Evaluation of Bolton's tooth width ratios in crowded and non-crowded dentitions in Class I and class II skeletal bases among the south Indian population: an in-vitro study. International Journal of Contemporary Dentistry 2010;1(3):99-106.

[17] Bernabe E, Villanueva KM, Flores-Mir C. Tooth width ratios in crowded and non-crowded dentitions. Angle Orthod 2004;74(6):765-8.

[18] Uysal T, Memili B, Usumez S. et al. Dental and Alveolar Arch Widths in Normal Occlusion, Class II division 1 and Class II division 2. Angle Orthod 2005;75(6):941-7.

[19] Hou HM, Wong RWK, Hagg EUO. The uses of orthodontic study models in diagnosis and treatment planning. Hong Kong Dental Journal 2006;3(2):10715 . 
[20] Gaidyte A, Baubiniene D. Influence of premolar extractions on tooth size discrepancy. Part two: analysis of Bolton values. Stomatologija, Baltic Dental and Maxillofacial Journal 2006;8(1):25-9.

[21] Stevens DR, Flores-Mir C, Nebbe B, et al. Validity, reliability and reproducibility of plaster vs digital study models: comparison of peer assessment rating and Bolton analysis and their constituent measurements. Am J Orthod Dentofacial Orthop 2006;129(6):794-803.

[22] Tong H, Chen D, Xu L, et al. The effect of premolar extractions on tooth size discrepancies. Angle Orthod 2004;74(4):508-11.

[23] Ciger S, Aksu M, Saglam-Aydinatay B. Interarch toothsize relationships of normal occlusion and Class II Division 1 malocclusion patients in a Turkish population. Hacettepe Dişhekimliği Fakültesi Dergisi 2006;30(4):25-32.

[24] Paredes V, Gandia JL, Cibrian R. Determination of Bolton tooth-size ratios by digitization and comparison with the traditional method. European Journal of Orthodontics 2006;28(2):120-5.

[25] Fattahi HR, Pakshir HR, Hedayati Z. Comparison of tooth size discrepancies among different malocclusion groups. European Journal of Orthodontics 2006;28(5):491-5.

[26] Golwalkar SA, Msitry KA. An evaluation of dental crowding in relation to the Mesiodistal crown widths and arch dimensions. The Journal of Indian Orthodontics Society 2009;43(2):22-9.

[27] Akyalcın S, Dogan S, Dincer B, et al. Bolton tooth size discrepancies in skeletal Class I individuals presenting with different dental angle classifications. Angle Orthodontist 2006;76(4):637-43.
[28] Antanas S, Giedre T. Effect of the lower third molars on the lower dental arch crowding. Stomatologija, Baltic Dental and Maxillofacial Journal 2006;8(3):804.

[29] Janosevic M, Filipovic G, Stankovic S. et al. Influence of the size of incisors on the occurrence of crowding. Medicine and Biology 2006;13(1):36-43.

[30] Othman S, Harradine N. Tooth Size Discrepancies in an orthodontic population. Angle Orthodontist 2007;77(4):668-74.

[31] Hong QU, Koirala R, Jun T, et al. A study about tooth size and arch width measurement. J Hard Tissue Biology 2008;17(3):91-8.

[32] Al-Rubayee MAH. The use of computer technology in dental arch crowding assessment. MDJ 2008;5(4):372-83.

[33] Jaiswal AK, Paudel KR. Applicability of Bolton's tooth size ratio for Nepalese population. J Nepal Dent Assoc 2009;10(2):84-7.

[34] Ling JYK, Wong RWK. Dental arch widths of southern Chinese. Angle Orthod 2009;79(1):54-63.

[35] Naveed A, Naeem S, Ahsan W. Mesiodistal dimension of maxillary anterior teeth: their clinical implications. Pakistan Oral \& Dental Journal 2010;30(2):394-7.

[36] Horton HM, Miller JR, Gaillard PR, et al. Technique comparison for efficient orthodontic tooth measurements using digital models. Angle Orthod 2010;80(2):254-61. 